\title{
CONFLICTIVIDAD SOCIO-TERRITORIAL EN QUINTANA ROO, MÉXICO: ENTRE EL TURISMO Y LA CONSERVACIÓN DE LA NATURALEZA
}

\author{
Sandra Grisel Flores Luis ${ }^{1}$, Enrique Propín Frejomil ${ }^{2}$ \\ Universidad Nacional Autónoma de México
}

\begin{abstract}
RESUMEN
Las investigaciones sobre conflictividad social se han centrado en el ámbito social (desde la Sociología y Antropología) y en el ambiental (con la Ecología política y la Economía ecológica), dejando de lado procesos más amplios, siendo el caso de las reconfiguraciones territoriales. La presente investigación aborda la conflictividad socio- territorial desde la disciplina geográfica. Con ello se logra evidenciar la pertinencia de las herramientas conceptuales de la Geografía en el ámbito de los conflictos sociales, teniendo como caso de estudio la reconfiguración territorial del estado de Quintana Roo, México, a través de su conformación socio- histórica. En este contexto se exponen los conflictos que se generan actualmente por el enfrentamiento entre agentes sociales que pugnan por el desarrollo turístico y por la conservación de la naturaleza. El problema es abordado desde la metodología cualitativa y la revisión bibliográfica y documental.
\end{abstract}

Palabras clave: conflictividad; territorio; turismo; conservación de la naturaleza; Quintana Roo.

\section{SOCIAL- TERRITORIAL CONFLICTIVITY IN QUINTANA ROO, MÉXICO: BETWEEN TOURISM AND NATURE CONSERVATION}

\begin{abstract}
Research on social conflict has focused on the social sphere (from Sociology and Antropology) and environmental (with political Ecology and Ecological Economics), leaving aside broader processes, such as territorial reconfigurations. This article addresses socio- territorial conflictivity from the geographical discipline. It's possible to demonstrate the relevance of the conceptual tools of Geography in the field of social conflicts, taking as a study case the territorial reconfiguration of the state of Quintana Roo, México, through its socio- historical conformation. In this context are exposed the conflicts that are currently generated by the confrontation between social agents who fight for tourism development and for the nature conservation. The problem is approached from the qualitative methodology and the bibliographic and documentary review.
\end{abstract}

Key words: Conflictivity; Territory; Tourism; Nature conservation; Quintana Roo.

${ }^{1}$ Posgrado en Geografía, Universidad Nacional Autónoma de México. E- mail: floresgris@gmail.com ${ }^{2}$ Instituto de Geografía, Universidad Nacional Autónoma de México. E- mail: propinfrejomil@igg.unam.mx

Fecha de recepción: 13 de agosto de 2019. Fecha de aceptación: 26 de diciembre de 2019 


\section{INTRODUCCIÓN}

El estado sureño de Quintana Roo, México, ha alcanzado fama mundial por su oferta turística, principalmente en la parte norte de su territorio, desde la década de 1970. La Secretaría de Economía (2017) reportó que el Producto Interno Bruto (PIB) de Quintana Roo en 2016 fue de 301, 890 mil millones de pesos, aportando el 1.6\% del PIB nacional. Las actividades terciarias contribuyeron con el $87 \%$ del PIB estatal. Dentro de estas actividades, las principales son la hotelería con 75. 610 mil millones de pesos, el comercio con 55, 797 mil millones y los servicios inmobiliarios y de alquiler de bienes inmuebles e intangibles con 37, 446 mil millones.

Esa estampa reconocida de mar turquesa, arena blanca y modernos conjuntos hoteleros se ha gestado a lo largo de un periodo largo y como resultado de la acción de diversos agentes sociales; llegando a constituirse como un eje de la macrorregión turística de acentuada polarización territorial del sureste del país (PROPÍN Y SÁNCHEZ, 2002). Además de la polarización, la selectividad territorial del destino ha dado el nivel de exclusividad alta con estadía alta de turistas extranjeros (PROPÍN, SÁNCHEZ Y ALVARADO, 2017). El posicionamiento de las costas de Quintana Roo (especialmente Cancún, Cozumel y la Riviera Maya) en el ranking de centros turísticos internacionales existen intereses del capital, nacional y extranjero, agentes gubernamentales, grupos hoteleros internacionales, operadores turísticos, entre otros. Sin embargo, del otro lado se encuentran los agentes locales que tienen intereses que pueden o no coincidir con los del gobierno e inversionistas. Es entonces que la categoría de conflictividad socio- territorial da luz a dinámicas que pudieran pasar desapercibidas en torno al enfrentamiento de territorialidades y a la reconfiguración de los territorios.

\section{POSICIONES COGNOSCITIVAS}

El conflicto, en la Teoría social, se ha abordado de dos formas: desde las teorías que buscan explicar a la sociedad y que lo entienden como un elemento disruptivo al equilibrio, y las propuestas que lo entienden como parte de la estructura de lo social. La propuesta del conflicto como un principio explicativo del funcionamiento general de la sociedad es clara en dos tradiciones principales de la teoría social: la inspirada en J.J. Rousseau (BOLÍVAR Y CUÉLLAR, 2008) y la que deriva del pensamiento de T. Hobbes (CARDONA RESTREPO, 2008).

Rousseau partió de la idea general de un Estado en equilibrio, del Estado como una forma de organización política que surge de la decisión de las personas que comparten un lazo social (sentimientos, costumbres, tradiciones y valores compartidos) y debe responder al interés común. Dicho 'lazo' define lo que es bueno o malo para el conjunto social y frena el desarrollo de intereses particulares; por lo que las relaciones sociales no son conflictivas pues el interés público trasciende a lo individual. En cambio, para Hobbes el ser humano no es sociable por naturaleza y no existen lazos sociales. La creación de leyes y de un pacto político es necesaria para que los sujetos en permanente guerra pueden convivir y dejar el estado de enemistad y lucha (CARDONA RESTREPO, 2008: 128). Así, el conflicto es parte de la naturaleza humana que se lleva hasta las formas sociales, pues existe una discordia subyacente a la sociedad que sólo puede ser controlada mediante la transferencia de los derechos individuales la formación política: el Estado civil.

En cuanto a la forma en que se ha abordado el conflicto en la Geografía, según sus matrices filosóficas- epistemológicas (ORTEGA VALCÁRCEL, 2010; CAPEL SÁEZ, 2012), la noción de conflicto se incorpora de distinta manera:

1. Conflicto como un 'desajuste' de las regularidades espaciales del sistema total, para la matriz racionalista positivista que destaca las regularidades observables de los fenómenos, la formulación de leyes y el sometimiento al rigor del análisis lógico de los datos empíricos ${ }^{3}$ (CAPEL SÁEZ, op. cit.).

\footnotetext{
${ }^{3}$ Éste elemento fue un aporte del grupo de científicos reconocidos como Círculo de Viena, hecho como rechazo a la metafísica e idealismo. Partían de los supuestos de que la realidad es coherente por eso puede ser expresada lógica y matemáticamente, todo está constituido por materia y no existe una separación entre las ciencias naturales y del espíritu (Capel, 2012). Para profundizar en el tema revisar Capel (2012) y Ortega (2000)
} 
2. Conflicto como parte consustancial de la vida social, desde la matriz racionalista- materialista dialéctica que establece que existe una realidad objetiva, (externa al observador), con movimiento (por tanto en constante cambio) y que debe ser entendida como totalidad.

3. Conflicto como parte de las vivencias de agentes que experimentan el mundo cotidiano con intencionalidades, conciencia, ideas y significados dados al espacio de manera diferenciada, experiencias de los lugares que pueden converger o divergir, para la matriz filosófica de la subjetividad.

La segunda matriz, responde a la tradición teórico-filosófica de Hobbes, centrada en el entendimiento de la sociedad con contradicciones inherentes, pues los sujetos y grupos sociales tienen objetivos contrapuestos que resultan en confrontación de intereses (LORENZO CADARSO, 2001: 238.). Esta es la idea central de la investigación que ha guiado el presente artículo: el conflicto es inherente a los fenómenos sociales y por ende, a los territoriales. En este sentido, se entiende que el territorio está atravesado por intereses y relaciones políticas, por lo cual existen actores, reglas, objetivos, prácticas específicas; lo cual nos llevó a utilizar una metodología cualitativa para abordar a los agentes sociales con sus diferentes grados de participación y decisión. Además, con la necesidad de hacer referencia a la condición histórica de la construcción de los territorios, el análisis bibliográfico y documental ha sido fundamental para reflexionar sobre la materialización de las relaciones sociales y por ende, de los territorios que se construyen en un tiempo determinado.

\subsection{CONFLICTIVIDAD SOCIO- TERRITORIAL}

La categoría conflictividad socio- territorial es una propuesta que busca incorporar distintos elementos que tanto los conceptos de conflicto ambiental, como conflicto socioambiental, dejan de lado. Conflicto ambiental está asociado a la forma particular que las instituciones gubernamentales han reducido distintas situaciones a una relación causal entre la existencia de recursos naturales en zonas ambientalmente vulnerables y la presencia de población en pobreza que presiona sobre esas áreas y las deteriora (FOLCHI DONOSO, 2001). Mientras que cuando se habla de conflicto socioambiental, se asocia con el neoliberalismo: la desregulación comercial, la apertura de mercados, la mercantilización del ambiente. Los conflictos socioambientales implican tres condiciones mínimas: escasez, deterioro o privación de los recursos naturales, que finalmente implican percepciones diversas (PONT- LEZICA, 2005).

El aspecto que se subraya aquí es la necesidad de entender los conflictos como consecuencia de la asimétrica distribución del poder en cuanto al control material y simbólico del territorio. Así entonces, con conflictos socio- territoriales se alude no solamente a la lucha entre agentes sociales opuestos, sino a la tensión entre ellos. Tensión que no solamente se produce por los recursos naturales, sino que responde a una realidad más amplia que se estructura en torno a contradicciones socio- históricas profundas (GUERRERO, 1999: 36). Siguiendo a Folchi, los conflictos aquí presentados son tensiones sociales con una temporalidad de larga duración, son estructurales (FOLCHI DONOSO, 2001), donde el territorio es producto del conflicto y tiene una esencia dual: como recurso y como espacio de vida, en él se redefinen las identidades y las prácticas de los sujetos.

\subsection{CONFLICTIVIDAD EN LA REVALORIZACIÓN DE LOS BIENES NATURALES}

La conflictividad socio- territorial se da en el momento en que distintas - territorialidades se enfrentan. En este contexto se reconoce la racionalidad dominante, caracterizada por la acción racional, instrumental, técnica, con un control centralizado, que busca resultados y que busca crear un orden cotidiano obediente y disciplinado. Mientras que la racionalidad de los actores no beneficiados que forman "contra-racionalidades" (SANTOS, 2000: 262) marcan un orden cotidiano donde se gestan los conflictos, que son portadas y fortalecidas por las minorías, los excluidos y las actividades tradicionales.

El capital está rigiendo toda actividad humana, y todos los espacios. Se suceden cambios que modifican la estructura social y económica local, instaura territorialidades excluyentes en los mundos rurales, lo cual crea conflictos con otras formas de territorialización como las que se expresan en las comunidades tradicionales, organizadas en torno a los vínculos familiares. 
(DOMÍNGUEZ y SABATINO, 2008). Hay un impacto negativo en los saberes productivos comunitarios, los lazos comunitarios y los proyectos políticos que se quedan sin referente, sin sustento material (LEÓN HERNÁNDEZ, 2011).

La superposición de territorialidades, de la razón local y la razón global, conlleva un proceso de territorialización- desterritorialización- reterritorialización, implica que en un mismo espacio social existen simultáneamente múltiples proyectos y prácticas políticas; se dan "territorialidades simultáneas múltiples o multiterritorialidades que se complementan y construyen a partir de sus tensiones y contradicciones" (SANTOS, op. cit.; LEÓN HERNÁNDEZ, op. cit.).

\section{RECONFIGURACIÓN TERRITORIAL EN QUINTANA ROO}

La conflictividad socio- territorial es uno de los ejes de análisis sobre la reconfiguración de los territorios. El enfrentamiento entre racionalidades conlleva transformaciones territoriales, el claro ejemplo de ello es la entidad federativa de Quintana Roo en México. Quintana Roo ha alcanzado fama mundial por su oferta turística, principalmente en la parte norte de su territorio, desde la década de 1970. Pero esa estampa reconocida de mar turquesa, arena blanca y modernos conjuntos hoteleros se ha gestado a lo largo de un periodo largo y como resultado de la acción de diversos agentes sociales.

MACÍAS ZAPATA (2002) establece que la creación del Territorio Federal de Quintana Roo ha sido explicada desde diferentes puntos de vista, dentro de los cuales sobresale la propuesta de ser "producto inmediato de la guerra de castas", de controlar a los grupos indígenas, colonizar y civilizar la región (LAPOINTE, 1983, en MACÍAS ZAPATA). Otra hipótesis habla de la influencia de un grupo político con interés por la riqueza forestal que apoyó la separación del territorio de Yucatán (CANTO, 1954, en MACÍAS). Pero para Macías falta incluir la influencia de los flujos comerciales que conformaron la organización administrativa fiscal, "reflejada a través de la instalación de las aduanas marítimas a lo largo del litoral, cuyo conjunto fue después la base de la jurisdicción política del territorio federal" (MACÍAS, op, cit.: 16). Quintana Roo se originó de una zona económica que adelantó a la zonificación política y administrativa. Evidencia de ello es el trazo de la infraestructura según el avance de la devastación de la selva y de la proyección de nuevas zonas para a explotación de las reservas forestales.

\footnotetext{
${ }^{4}$ La Guerra de Castas fue una rebelión de las comunidades mayas campesinas, iniciada el 30 de julio de 1847 en Tepich. Yucatán. Con el dominio territorial de las haciendas de henequén en la zona, los grupos mayas aún autónomos que vivían de las siembras, vieron su mundo transformarse y ante el riesgo de convertirse en peones tomaron las armas e iniciaron una conflagración que duraría hasta 1901 cuando el ejército mexicano, liderado por el general Ignacio A. Bravo entra al santuario maya de Santa Cruz (hoy Felipe Carrillo Puerto).
} 


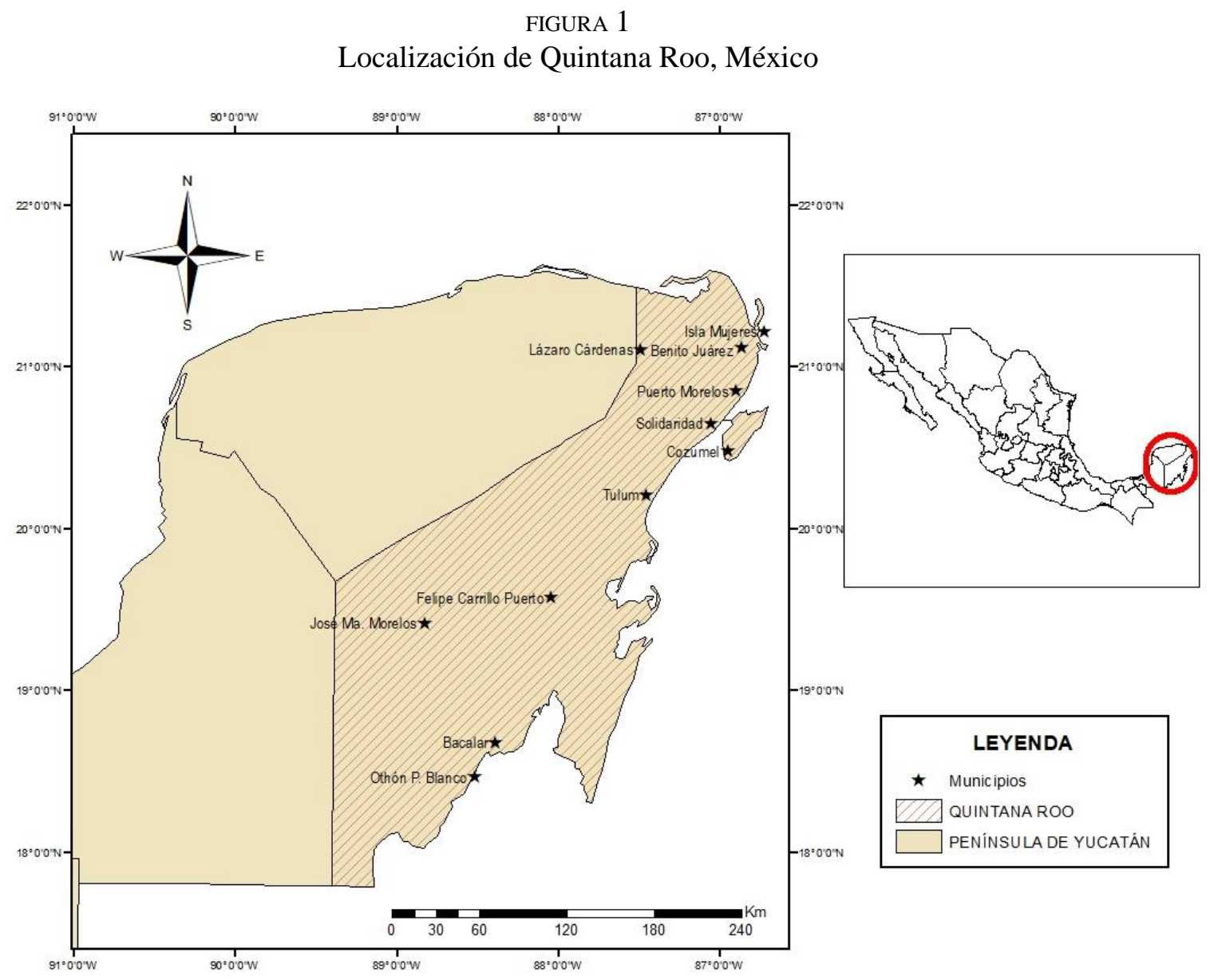

Fuente: elaborado sobre la base de INEGI, 2018.

Teniendo ese antecedente histórico y conceptual, se reflexionó en torno a la reconfiguración conflictiva del territorio quintanarroense dado por las acciones de diferentes agentes, principalmente el gobierno y empresarios e inversionistas con determinados intereses que favorecieron y favorecen determinadas actividades, flujos económicos y por ende, tensiones con otras territorialidades. Se observa la diferencia entre el norte, centro y sur de la entidad en cuanto la forma de poblamiento, la puesta en marcha de actividades económicas y los beneficios obtenidos por la población en general. Para ello se hace una división temporal del proceso sociohistórico contemporáneo: el reparto agrario, los emprendimientos comunitarios y el turismo de masas y naturaleza.

\subsection{EL REPARTO AGRARIO Y LAS CONCESIONES FORESTALES}

El 24 de noviembre de 1902 se decretó la creación del territorio federal de Quintana Roo, la división administrativa respetó las antiguas tres zonas demarcadas por los flujos económicos: el sur con la aduana y el pontón de Payo Obispo; el noreste con el establecimiento de las compañías colonizadoras $^{5}$, y el centro- oriente con el control militar de Bacalar, Xcalac y Chan Santa Cruz. De allí que se erigieran tres distritos: norte con los municipios de Isla Mujeres, Cozumel y Holbox;

\footnotetext{
${ }^{5}$ El gobierno federal fomentó el establecimiento de dos empresas que explotarían los bosques tropicales: el Cuyo y Anexas y la Compañía Colonizadora de la Costa Oriental. Éstas debían fraccionar y deslindar la selva y crear centros de población. En los espacios concesionados se establecieron ranchos ganaderos, se explotó el palo de tinte y de chicozapote, se sembró maíz, vainilla y tabaco. A partir del funcionamiento de estas dos compañías se establecieron poblados importantes, como Leona Vicario, el Meco (hoy Puerto Juárez, Solferino y Chiquilá).
} 
centro con Santa Cruz de Bravo; y al sur con los municipios de Payo Obispo, Bacalar, Xcalak e Icaiché.

En los tres distritos la colonización no tuvo resultados alentadores. La población de Payo Obispo sólo contaba con 238 habitantes en 1904; Bacalar había sido abandonada en 1907 cuando los militares se retiraron después de la Guerra de Castas; en el norte, a pesar de trece años de funcionamiento dela Compañía Colonizadora de la Costa Oriental sólo se habían consolidado dos pueblos, Puerto Morelos y Yalikin; en la zona centro sólo Santa Cruz tuvo un desarrollo más menos constante, pero terminó siendo abandonada y casi destruida ${ }^{6}$.

Al territorio en cuestión la lucha revolucionaria iniciada en 1910 llegó hasta 1912, mientras, la principal actividad era la explotación del chicozapote, plasmada en el territorio de la siguiente manera (VILLALOBOS GONZÁLEZ, 2015): al norte, la Compañía Colonizadora de la Costa Oriental de Yucatán había adaptado su infraestructura con una vía de tren Decauville portátil que sacaba la producción hasta Vigía Chico en un recorrido de 10 a 14 horas. En el Distrito Centro la explotación de la concesión fue muy difícil por el asedio de los grupos mayas y porque solo contaba con dos caminos de herradura: uno desde Santa Cruz de Bravo hasta Peto, Yucatán (13 días de recorrido) y el segundo que iba de Santa Cruz de Bravo hasta la orilla de la laguna de Bacalar (recorrido en 2 o 3 días). Finalmente, en el Distrito Sur la vía fluvial del río Hondo permitió una importante dinámica para el tránsito de los productos forestales extraídos y de las mercancías que abastecían a los campamentos.

Al término del movimiento revolucionario se plantearon dos modalidades de solución a la problemática del reparto agrario: a) la repartición de 'montes' para la extracción del chicle y, b) la repartición de ejidos. Desde 1928 se realizaron las primeras solicitudes de tierra, pero fue hasta mediados de la siguiente década que la repartición de tierras a campesinos quintanarroenses comenzó. El proceso de reforma agraria estuvo condicionado por las características naturales del territorio: poca productividad de los suelos (escasa profundidad) y a los enormes recursos forestales: madera y resinas. Los primeros ejidos en crearse, entre 1930 y 1940, se localizaron en la ribera del río Hondo, destinados a la explotación forestal y con el objetivo de reforzar la frontera mexicana con la colonia británica de Belice.

A partir de 1930 se otorgaron derechos sobre la tierra bajo dos criterios: el reconocimiento de posesión de la tierra a los campamentos chicleros y poblados mayas y, el otorgamiento de tierra con criterios forestales de 420 ha por ejidatario, dividida en cinco secciones, cada una debía ser explotada en periodos de cinco años para permitir la regeneración del arbolado. De esta forma, los ejidos creados entre 1930 y 1940 fueron planeados para desarrollar actividades económicas forestales (ROMERO, 2008). Las poblaciones que se fundaron con esta repartición fueron transformadas en 'poblados de concentración' que asimilaban a los pequeños núcleos de población diseminados en el interior de la selva (MACÍAS, op. cit.).

A partir de 1940, se frenó la Reforma Agraria y durante el gobierno de Miguel Alemán del reparto se pasó a la enajenación del bosque ejidal para entregarlo a empresas paraestatales. Aunque los campesinos teóricamente no perdieron los ejidos, el gobierno se reservaba el derecho de decidir a quién concesionaba el monte para su aprovechamiento. La explotación forestal fue declarada de interés público, en un contexto donde la sustitución de importaciones era la política que reemplazó a los proyectos posrevolucionarios de reforma social y política (Íbid.). Para Quintana Roo, el trabajo de BRAY y MERINO (2005) establece que la empresa beneficiada con la concesión, Maderas Industrializadas de Quintana Roo (MIQRO) ${ }^{7}$, a diferencia de los

\footnotetext{
${ }^{6}$ Eventualmente Santa Cruz fue utilizada por el gobierno federal como colonia penal donde criminales y presos políticos convivían en un ambiente de trabajo forzado, enfermedades gastrointestinales y maltratos. Fue hasta el gobierno de Venustiano Carranza que la colonia se desarticuló, se le devolvió el poblado a los mayas y la capital se trasladó a Payo Obispo. Sin embargo los mayas destruyeron parte de la infraestructura construida como líneas telegráficas, vías férreas e inmuebles. Una epidemia de viruela orilló a muchos de ellos a dejar el poblado y dividirse en tres grupos, unos se establecieron en Xcacal, otros en Chunpom y los últimos en Yodzonot- Guardia (SANDOVAL, 2011).

${ }^{7}$ La empresa pagaba derecho de monte al gobierno por el uso de los terrenos nacionales, para los terrenos ejidales existió una cuota fijada por el gobierno federal por cada metro cúbico extraído. El pago a los ejidos estaba mediado por la Secretaría de la Reforma Agraria que era comisionada de recolectar las cuotas, "se
} 
contratistas: "basó las extracciones en planes de manejo e inventarios forestales, construyó una red de caminos que los ejidos utilizaron posteriormente y contrató preferentemente mano de obra de los propios ejidos, lo que sirvió en alguna medida de capacitación a los ejidatarios" (BRAY y MERINO, op. cit:: 21).

Ya en la década de 1970 comenzó la segunda etapa del reparto agrario, pero a diferencia de la anterior no se realizó sobre los terrenos de las antiguas concesiones forestales, los Nuevos Centros de Población Ejidal (NCPE) se instalaron en las tierras de los ejidos forestales entregados en el cardenismo. Se fundaron principalmente al sur de la entidad, en la ribera del Río Hondo y la cuenca de Ucúm, tuvieron desde el principio una vocación agrícola. A cada ejido se le dotó con superficies menores, 10 ha de riego o hasta 50 ha de temporal. La pequeña superficie repartida permitió la recepción de colonos provenientes de Jalisco, Veracruz, la Comarca lagunera, Michoacán y Tabasco.

\subsection{EMPRESAS FORESTALES COMUNITARIAS}

Después de un largo periodo de concesión forestal a la empresa paraestatal maderera, en 1983 se dio fin al contrato. En paralelo se inició con la política federal de fomento a la participación de los dueños de bosques y selvas en el manejo y aprovechamiento. Como lo establecen Bray y Merino "se empezó así a plantear que para asegurar el abasto de materia prima los campesinos debían manejar sus propias empresas de extracción, contando con el apoyo de profesionistas forestales" (Íbid.: 88).

En el periodo presidencial de Miguel de la Madrid (1982-1988) se dio fin al reparto agrario y se disminuyó la participación del Estado en la economía, por lo que las paraestatales fueron desapareciendo, en el caso del ámbito forestal, las concesiones también terminaron. Dicha situación se acompañó de un esfuerzo por apoyar a las comunidades que habían sido afectadas por las concesiones y que mostraron interés por realizar la extracción por ellas mismas. La ley forestal de 1986 fue la materialización de este cambio pues anuló el sistema de concesiones forestales, reconoció el derecho de las comunidades para aprovechar directamente sus bosques y suprimió cualquier forma de rentismo.

En Quintana Roo el gobierno le devolvió a los ejidos el control de sus montes a través de la implementación del Plan Piloto Forestal (PPF) en 10 ejidos que tenían una base organizativa y experiencia de localización y delimitación de áreas anuales para corte, y las demás actividades referentes a la extracción, como tumba, troceo y transporte (CALDERÓN, 1999). Es entonces que los conocimientos que los ejidatarios habían adquirido al trabajar en la MIQRO sirvieron para fortalecer las nuevas tareas de aprovechamiento. Sobre esto nos dice Calderón (1999) que la tradicional actividad chiclera también era fuente de conocimientos sobre la composición y ecología de la selva.

Se observa que el PPF no sólo se refería a la actividad maderera, sino que incluía otros aspectos: campesino, comercial, industrial e institucional. El aspecto campesino era el eje y tuvo las siguientes características: creación de un Área Forestal Permanente (AFP); establecimiento de un ciclo de corte de 25 años, dividiendo el área en 25 porciones para explotar una por año; realización de inventarios forestales y, aprovechamiento de un mayor número de especies de maderas. En cuanto al aspecto comercial se buscó guiar y fortalecer a los ejidatarios en su papel de negociadores y gestores en las actividades de extracción y comercialización de sus recursos; ello a través de asistencia técnica y capacitación. Los campesinos controlaron la comercialización y lograron mejorar los precios, colocaron las maderas no preciosas en el mercado; los ingresos de los ejidos aumentaron y algunos lograron capitalizarse y adquirir maquinaria de aserradero y/o carpintería.

Observando estos avances y temiendo que al final del PPF el gobierno no reconociera la organización comercial estructurada por los ejidatarios, se creó una organización formal que tuviera la capacidad de contratar equipo técnico para ser asesorados. Con la creación de dos sociedades civiles en 1986 se logró dar continuidad al PPF: Sociedad de Productores Forestales

encargaba de la cobranza, se quedaba con el $25 \%$ para un fondo común y asignaba el $75 \%$ a obras de beneficio colectivo del ejido correspondiente" (CALDERÓN MALDONADO, 1999: 45). 
Ejidales de Quintana Roo S.C. (SPFEQR), integrada por los 10 ejidos con los que trabajaba el Plan Piloto; y la Organización de Ejidos Forestales de la Zona Maya, en la que participaron originalmente 16 ejidos mayas. Ambas trataron de posicionarse como organizaciones que cuidaran los intereses de los ejidatarios en las negociaciones políticas con el gobierno y para la negociación en bloque con los comerciantes de madera.

El gobierno estatal, a través de la Secretaría de Protección Forestal siguió apoyando el modelo del PPF para frenar la deforestación y en 1989 lo extendió a todo el territorio estatal, creando el Plan Forestal Estatal (PFE). Para lo cual se llevó a cabo una delimitación y un inventario general para establecer nuevas áreas forestales permanentes, a ese conjunto se le denominó Reserva forestal estratégica bajo manejo (Íbid.: 52). En este contexto se erigieron entre 1990 y 1991 otras tres organizaciones de ejidos forestales: Organización de Ejidos Productores Forestales "Chaktemal", Sociedad de Pueblos Indios Forestales "Tumbén Kuxtal" y Organización de Pequeños Productores Forestales de Quintana Roo.

El trabajo con los ejidos adherentes al PPF y luego al PFE logró tener frutos por la presencia del equipo técnico e investigadores miembros del Acuerdo México- Alemania. Pero también por la presencia de otras organizaciones, como Overseas Development Administration (ahora DIFD) que contribuyó financiera y técnicamente para la construcción de caminos forestales; la Fundación McArthur que asesoró a los ejidatarios en la elaboración de inventarios forestales y, la Forest Stewardship Council (FSC) que otorgó sellos de certificación a los ejidos por su buen manejo forestal, ampliando los espacios internacionales para la comercialización. Dichos agentes no gubernamentales cobraron mayor fuerza en el contexto de neoliberalización de las políticas públicas, pues al retirarse el Estado del sector forestal, la poca inversión que se daba en los proyectos de forestería comunitaria muchas veces provino de agencias internacionales o de las organizaciones civiles nacionales y extranjeras.

Por parte del gobierno no hubo inversión en los proyectos, no se desarrolló infraestructura de caminos, ni se fomentó el desarrollo tecnológico para que la producción tuviera valor agregado. Es más, con la reforma a la legislación agraria de 1992 para crear un mercado de tierras se implementó el Programa de Certificación de Derechos Ejidales (Procede) que reconocía derechos de propiedad particulares sobre las parcelas agrícolas y los solares urbanos. Con la Ley forestal de 1992 se legalizó nuevamente el rentismo forestal y se permitieron las asociaciones entre comunidades y empresarios privados (BRAY Y MERINO, op. cit.). Lo cierto es que desde 1994, con la apertura de las fronteras a la madera y productos anexos de otros países, el panorama de la industria y comercialización de la madera se hizo más difícil.

\subsection{TURISMO DE MASAS Y CONSERVACIÓN DE LA NATURALEZA}

En el contexto del fin de la producción forestal masiva en Quintana Roo y teniendo como problema de fondo la baja densidad poblacional, se reorientó su actividad económica con un plan de ocupación de las fronteras marítimas y ribereñas ${ }^{8}$, la principal estrategia fue el Proyecto Cancún, que formaba parte de la política de Centros Integralmente Planificados del gobierno federal. Tenía como polo de desarrollo a Cancún y abarcaba Isla Mujeres y Cozumel. Antes de este proyecto la oferta turística consistía solamente en hospedajes y restaurantes familiares, principalmente en Cozumel (BALAM RAMOS, 2010).

Uno de los principales objetivos fue generar divisas para el país, y como objetivos conexos se tenía el desarrollar la economía de la región, crear empleos para la población local y aminorar el impacto regional que se avecinaba por la decadente industria henequenera de Yucatán. En 1971, el gobierno federal apoyó la construcción del aeropuerto internacional de Cancún junto con el Banco de México y préstamos del Banco Interamericano de Desarrollo (BID) por 21 millones de dólares. El interés del gobierno mexicano en reactivar la economía de la región oriental de la Península de Yucatán fue aprovechado por un grupo de banqueros que "convencieron a Ernesto Hurtado, director del Banco de México, al Secretario de Hacienda, Antonio Ortiz Mena -padre

\footnotetext{
${ }^{8}$ El Programa tuvo tres ejes: la Ocupación y Desarrollo de las Costas que promovió veinte cooperativas pesqueras y la construcción de infraestructura carretera; Proyecto de la Frontera con Belice que apoyó la creación de los NCP en la ribera del río Hondo; y el proyecto Cancún.
} 
del Desarrollo Estabilizador- y finalmente al presidente, Gustavo Díaz Ordaz" (ROMERO MAYO, 2008:189).

En 1974, se fundó el primer hotel en la isla de Cancún, el Playa Blanca; seguido de 14 más, resultando en una disponibilidad de 1,500 cuartos. A partir de entonces se ha tenido un crecimiento constante en la oferta hotelera. En 1981, había 13 hoteles de cinco estrellas y 18 de cuatro. En 1987, aumentó a seis de gran turismo, 16 de cinco estrellas y 30 de cuatro. Para 1996, alcanzó el primer lugar nacional de ocupación hotelera (Íbid., 2008). Se observa que luego de una disminución notable en la llegada de turistas de 2008 a 2009, se recupera y llega a alcanzar la impresionante cifra de 11, 522, 815 visitantes en 2017 (Secretaría de Economía, 2017). Para satisfacer la demanda de todos los visitantes, los gobiernos federal y estatal han promovido la inversión directa, principalmente la extranjera. En 2017, Quintana Roo recibió 442 millones de dólares en este rubro, el 1.5\% de la Inversión Extranjera Directa (IED) en México.

Cancún fue la punta de lanza de la reconfiguración territorial en todo el estado. Se avanzó sobre nuevas zonas que formaban parte del área de influencia turística y que representaron nuevas opciones o alternativas complementarias para los visitantes. El desarrollo turístico no ha sido uniforme. En la zona central del estado ha tenido niveles muy bajos. Mientras que al sur la crisis económica de 1992 y la entrada en vigor del Tratado de Libre Comercio que permitió la entrada de productos de importación, no ha permitido que la actividad turística se desarrolle. Es posible hablar de la configuración territorial de Quintana Roo como asimétrica, donde el norte es próspero, el centro está marginado y el sur mínimamente desarrollado.

Para contrarrestar esa asimetría territorial y lograr un equilibrio del desarrollo se impulsó la inversión en el Mundo Maya, en lo denominado Costa Maya, que es el litoral de playas de cerca de $130 \mathrm{~km}$ desde Punta Herrero (zona sur de la Reserva de Sian Ka'an) hasta Xcalak (casi frontera con Belice). En esa área se encuentra Mahahual, un poblado donde se construyó un muelle para la llegada de cruceros, y a partir del cual se han estructurado servicios complementarios para los visitantes, como paseos por la selva, visitas a zonas arqueológicas cercanas (Chacchoben, Kohunlich, Dzibanché, Kinichná) o a la laguna de Bacalar.

Además, se han puesto en marcha acciones, las cuales han girado en torno a la construcción de espacios rurales 'competitivos', que respondan a las demandas del mercado nacional e internacional. Una de dichas acciones fue el desarrollo de proyectos de turismo sustentable, buscando involucrar a los habitantes locales en la planeación y manejo de los proyectos, dándoles acceso a los recursos y las ganancias económicas pero sin sustituir el modo de vida tradicional.

Por otra parte, para las autoridades estatales (en concomitancia con lo establecido desde las instituciones federales) el crecimiento económico y el desarrollo deben ser acompañados por el cuidado al medio ambiente. Gran parte de las comunidades rurales de Quintana Roo, al localizarse en áreas de gran valor ambiental han sido incorporadas a los espacios de conservación, lo cual ha significado otro cambio en su estructura territorial. El turismo alternativo se ha visto como una actividad que permite alcanzar tan importante objetivo, pues teóricamente representa la posibilidad de emplear a los habitantes de la zona en actividades de bajo impacto al medio ambiente.

Las acciones de conservación tienen una clara tendencia hacia el turismo alternativo, pues pareciera ser la oportunidad de conservar los recursos y permitir el desarrollo económico de cientos de comunidades que habitan las áreas de valor ambiental. Aunque a esta situación habría que sumarle que la oferta turística de sol y playa está siendo insuficiente para la cada vez más creciente demanda de "experiencias diferentes de contacto con la naturaleza y con culturas diversas"; entonces se entiende este cambio del espacio rural como parte de la reconfiguración que el turismo en la Península de Yucatán está llevando a cabo desde hace más de 30 años. Los espacios naturales están siendo refuncionalizados con objetivos mercantiles en torno al cuidado y preservación de la riqueza natural (FLORES LUIS, 2013).

\section{CONFLICTIVIDAD SOCIO TERRITORIAL: ENTRE EL CRECIMIENTO ECONÓMICO, LA FRAGMENTACIÓN SOCIAL Y LA DEGRADACIÓN AMBIENTAL}

Este recorrido histórico permite entender la configuración territorial actual de Quintana Roo, donde el turismo es el pilar del crecimiento económico y hay una clara disminución de las 
actividades agropecuarias y forestales. Además de un claro desequilibrio territorial, tanto de desarrollo, como de crecimiento urbano entre el norte y el centro y sur de la entidad. Quintana Roo es un espacio fragmentado y degradado, en gran parte por las políticas públicas que hasta la fecha se han puesto en marcha. A continuación presentamos las formas en que la fragmentación y degradación coexisten con el alardeado crecimiento económico, y cuáles han sido hasta ahora los resultados de esa interacción.

Se subrayan tres situaciones conflictivas que actualmente se presentan por el crecimiento económico del turismo ${ }^{9}:$ 1) el avance de la infraestructura turística sobre los bienes naturales, que se manifiesta en degradación ambiental, 2) la reconfiguración territorial, con la desarticulación como expresión en auge y, 3) el abandono de las zonas rurales que exhibe el rezago social en crecimiento. Todos ellos, son manifestaciones de la conflictividad entre el turismo y la conservación del patrimonio natural que originalmente dio a Quintana Roo la oportunidad de ser polo de atracción turística de clase mundial.

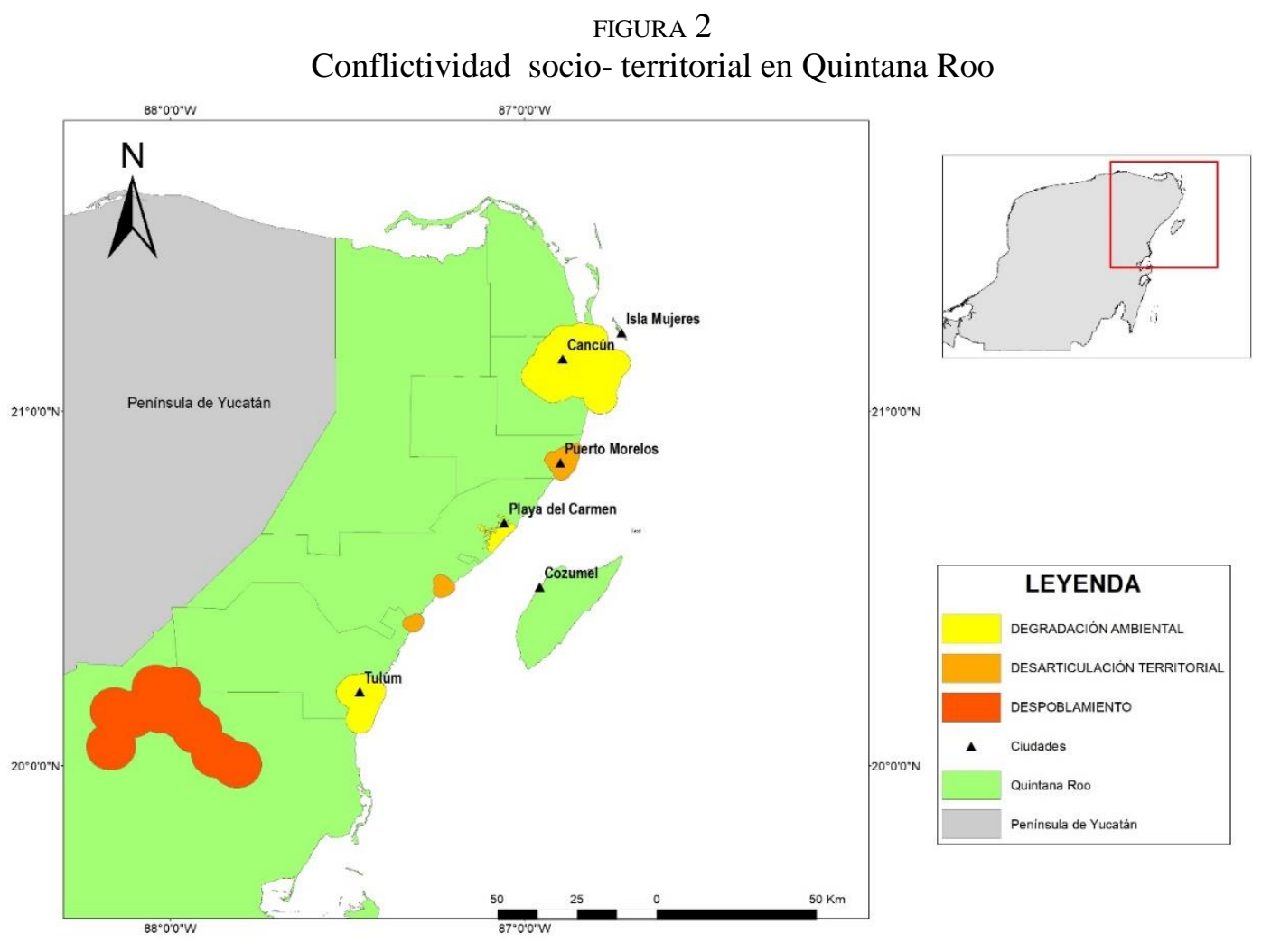

Fuente: Elaboración propia

La primera de las situaciones conflictivas deriva de la llegada de las inversiones al ramo turístico, por el aumento de infraestructura y el crecimiento de servicios inmobiliarios y de alquiler. Ya no solo se observa el crecimiento de la ciudad de Cancún, sino que desde 1990 la tendencia del turismo de avanzar sobre nuevos espacios se ha concretado hacia el sur del litoral,

\footnotetext{
${ }^{9}$ La Secretaría de Economía (2017) reportó que el Producto Interno Bruto (PIB) de Quintana Roo es 2016 fue de 301, 890 mil millones de pesos, aportando el 1.6\% del PIB nacional. Las actividades terciarias contribuyeron con el $87 \%$ del PIB estatal, mientras las actividades secundarias tuvieron el $12 \%$ y las primarias sólo el $1 \%$.

Dentro de las actividades terciarias, las principales son la hotelería con 75. 610 mil millones de pesos, el comercio con 55, 797 mil millones y los servicios inmobiliarios y de alquiler de bienes inmuebles e intangibles con 37, 446 mil millones.

Solamente han existido tres eventos que han afectado el crecimiento del PIB estatal: el huracán Wilma (2005) bajó el PIB de 7.3\% a 4.9\%; la crisis financiera internacional (2008) pasando a tasas de $1.2 \%$; y el virus de influenza (2009) que resultó en una tasa negativa de $-9.2 \%$.
} 
conformándose la Riviera maya. A lo que se le suma el proyecto de Costa Maya que busca un crecimiento turístico al sur del estado, desde Punta Herrero hasta Xcalak.

La infraestructura turística y los servicios conexos han significado el deterioro de los ecosistemas del estado, el lagunar principalmente en Cancún, el de manglar en todo el litoral y el coralino en el arrecife mesoamericano que corre frente a las costas del estado. En el primero de los casos, la degradación del ecosistema lagunar se presenta a pesar de que se construyeron plantas de tratamiento de aguas servidas en la isla al lado de la laguna y conductos de evacuación de aguas de lluvia pues se vierten en la laguna Nichupté. Además, algunos hoteles y centros comerciales conectaban sus conductos de aguas servidas a los conductos de agua de lluvia. A lo que se le suma que la pavimentación del $80 \%$ de la isla impide la filtración de agua de lluvia y dicho líquido escurre hasta la laguna llevando metales pesados, aceites y diversos químicos solubles.

La segunda situación de degradación ambiental se presenta por el rápido avance de la construcción de las zonas hoteleras. Se han realizado sobre la duna costera, lo cual implicó la remoción de vegetación natural de la playa y el relleno de la zona de manglares, lo cual eleva su vulnerabilidad ante huracanes y lleva a la erosión de los arenales. En la zona de Cancún se ha tenido que invertir en inyección de arena para seguir teniendo playas atractivas.

El caso del arrecife de coral está directamente relacionada con dos hechos: la conducción de las aguas servidas de los poblados de la costa que muchas veces va sin tratamiento al mar; y la llegada de cruceros a los puertos del estado. En este último caso, se ha visto el blanqueamiento, enterramiento o destrucción de los bosques arrecifales por los contaminantes vertidos por los barcos: aguas jabonosas, aguas negras, aguas de cocina, desechos orgánicos, residuos de combustibles, entre otros.

Como lo establecen RUBIO et al. (2010) hay una crisis ambiental en la costa de Quintana Roo y se debe a que la sustentabilidad solo existió en el discurso y no fue tomada en consideración por el Fondo Nacional de Fomento al Turismo; no hay una coordinación adecuada entre los tres niveles de gobierno para definir una planificación a largo plazo; primacía del crecimiento económico y no al desarrollo social y económico; intereses personales de grupo antepuestos a los sociales; falta de vigilancia a los ordenamientos territoriales (RUBIO et al, 2010: 180).

El segundo punto a reflexionar como resultado del crecimiento de la actividad turística, y situación de conflictividad es la reconfiguración territorial que se manifiesta en tres fenómenos: a) polarización regional del bienestar social; b) segregación socio-espacial urbana y, c) desarticulación territorial en la línea de costa. Todos ellos relacionados con la alta tasa de crecimiento demográfico estatal, Quintana Roo presenta una tasa del 3.1 por ciento anual, mientras que el resto del país crece a razón de 1.8 por ciento. La migración hacia las ciudades, ya sea interna o proveniente de otras entidades del país y hasta del extranjero, muestra los siguientes números (INEGI, 2016): en 2000 el 56.4\% de la población del estado era nacida en otra entidad o en otro país, para 2010 fue el $54 \%$ y para 2015 el $54.1 \%$. Los municipios con mayor porcentaje de población nacida en otro estado o país son Solidaridad (67.8\%) y Benito Juárez (63\%), además de Isla Mujeres (55\%), Tulum (50.3\%) y Cozumel (47.5\%).

La primera de las manifestaciones territoriales es la polarización del bienestar y lo vemos reflejado en indicadores de servicios en la vivienda y analfabetismo. Son los municipios de la zona norte, del Quintana Roo turístico, los que tienen mejores porcentajes en cuanto a las viviendas con piso diferente de tierra: Cozumel 98.9\%, Benito Juárez 98.6\% y Solidaridad 98.1\%, frente a los municipios de la zona maya, Felipe Carrillo Puerto que tiene 90.4\%, Bacalar 91.2\% y José Ma. Morelos con 92.9\%.

El 98.8\% de las viviendas quintanarroenses cuenta con energía eléctrica. Los municipios que tienen más bajos porcentajes de cobertura de dicho servicio son los municipios del centro del estado Lázaro Cárdenas y José Ma. Morelos (96.4 y 96.5 por ciento, respectivamente). En cuanto al agua potable entubada en la vivienda se tiene una cobertura del $98.2 \%$ del total estatal. Resalta que los municipios con menor cobertura del servicio son municipios turísticos: Isla Mujeres, Benito Juárez y Cozumel (92.3 por ciento el primero y 97.9 los dos segundos). La disposición de drenaje alcanza el $97 \%$ de las viviendas del estado. En este caso son los municipios del centro del estado, de la zona maya, los que tienen los porcentajes más bajos: Felipe Carrillo Puerto 77.3, Lázaro Cárdenas 80.2 y José Ma. Morelos 80.7. 
Por otra parte, la tasa de analfabetismo, como indicador de bienestar de la población, retoma a la población de 15 años y más que no saben leer ni escribir. Los municipios con mayor rezago en este ámbito son Bacalar (12.9\%), al sur de la entidad; José Ma. Morelos (11.8\%), Felipe Carrillo Puerto (11.7\%) y Lázaro Cárdenas (11.2\%), de la zona maya. En cuanto al promedio de escolaridad de la población de 15 años y más son los municipios de Benito Juárez, Solidaridad y Othón P. Blanco, con 10, 9.9 y 9.7 años respectivamente, los mejor posicionados. Mientras que los más bajos son Bacalar (7.4 años), Lázaro Cárdenas (7.5 años) y José Ma. Morelos (7.5 años).

Con estos datos damos cuenta de la continuidad del proceso territorial que posicionaba al norte de la entidad como la más desarrollada, antes por las concesiones forestales y la explotación del chicle, ahora por el desarrollo turístico; el sur menos próspero, con municipios que continúan con actividades agropecuarias y forestales; y el centro rezagado y excluido del crecimiento económico general.

La segunda de las manifestaciones territoriales se enuncia como la segregación socio- espacial, principalmente observada en las zonas turísticas. En el caso de Cancún, la planeación urbana original visualizaba a la ciudad como el espacio de residencia de la población trabajadora de los hoteles y centros turísticos. Sin embargo, la llegada masiva de migrantes laborales y la incapacidad del gobierno para enfrentar la dinámica social, ha llevado al crecimiento desestructurado de la zona. Castillo y Villar nos hablan de un conjunto urbano integrado por tres ciudades colindantes pero segregadas social y funcionalmente: ciudad para los turistas, ciudad de sectores medios y altos ingresos y ciudad de los trabajadores de menores ingresos (CASTILLO y VILLAR, 2011: 94). Hay una división territorial formal: entre super manzanas (colonias dentro de la ciudad) y las regiones (zonas de la periferia). Pero hay una división implícita que emana de la cercanía o lejanía al centro turístico, entre más alejados, más marginados, menor calidad de vida o carencia de servicios públicos, violencia en espacios públicos y dentro de los hogares (ALAVEZ SAN PEDRO et al., 2017).

Este escenario de ocupación irregular del territorio por familias de bajos ingresos data de la década de los 80 cuando se constituyó la franja ejidal con asentamientos resultado de invasiones de tierras que luego fueron regularizados, pero que tienen servicios públicos precarios. En la actualidad, se observa la conformación de dos anillos: desde el centro hacia el norte y poniente, zona que presenta los mayores niveles de segregación socio- espacial y la zona central y turística que tiene cobertura total de servicios, mejores condiciones de vivienda y hacia ellas se dirigen en gran medida las inversiones públicas en infraestructura y equipamiento (CASTILLO y VILLAR, op.cit.).

La segregación socio-espacial, a la luz del bienestar de la población, incorpora indicadores de educación, servicios de salud, acceso a servicios urbanos y nivel de ingreso. Sobre los dos primeros podemos mencionar que la población de 3 a 5 años que asiste a la escuela es baja en los municipios de Solidaridad (50.5\%), Benito Juárez (54.3\%) e Isla Mujeres (55.8\%), todos ellos municipios turísticos. Mientras que las personas de 6 a 14 años que asisten a la escuela también es menor en Solidaridad (94.9\%), Isla Mujeres (95.6\%) y Benito Juárez (96.3\%).

En cuanto a la cobertura de salud, se observa que la afiliación a dichos servicios ha mostrado avances importantes entre 2000 y 2015 , pasando de $46.2 \%$ de afiliados a $80.8 \%$. Los municipios con peores porcentajes de cobertura son Solidaridad (76.3\%), Benito Juárez (77.4\%) y Tulum (79.4\%), con claras diferencias de más de 15 puntos porcentuales respecto al primer lugar: Bacalar con $91.7 \%$. Es el norte 'turístico' el que presenta los peores números, en gran medida por la precariedad laboral en la que cientos de migrantes viven.

No sería aventurado decir que estos indicadores están reflejando las condiciones precarias de los habitantes de las "regiones" y de los asentamientos irregulares que crecen día con día. Para enero de 2018 se calculaban 300 asentamientos irregulares donde vivían unas 60 mil personas, principalmente en Benito Juárez y Solidaridad (RANGEL, 2018). Dichos asentamientos se establecen en zonas ya urbanizadas como en áreas verdes. Con sus propios recursos consiguen los servicios básicos: conexiones irregulares a la red de energía eléctrica, compran pipas de agua o extraen de pozo, hacen fosas sépticas o vierten el agua de desecho en cenotes. Esta cara de la urbanización no es la que se publicita por todos los medios de comunicación masiva, pues la pobreza no vende ni posiciona al destino turístico de clase mundial. 
La tercera de las manifestaciones de la reconfiguración territorial por las actividades turísticas es la desarticulación territorial (social y funcional) en la línea de costa de la llamada Riviera Maya, desde Puerto Morelos hasta Punta Allen, con tres puntos principales del fenómeno: Puerto Morelos, Puerto Aventuras y Akumal. Dicha desarticulación también es nombrada como un modelo de desarrollo de apartheid (Córdoba y Ordóñez y García de Fuentes, 2003), el cual consiste en una separación material de los complejos hoteleros y parques turísticos del lado de litoral y las ciudades o pueblos del otro lado de la carretera federal 307 (que corre de Cancún a Chetumal).

En esas circunstancias se encuentra Puerto Morelos, con zona hotelera y residencial frente al mar; del otro lado las colonias populares que conforman el pueblo de Puerto Morelos. Asimismo Puerto Aventuras, con su marina de lujo tipo mediterráneo, empresas turísticas, escuelas privadas, departamentos y segundas residencias; y al otro lado el pueblo de Puerto Aventuras sin acceso al mar. También es el caso de Akumal, con su fraccionamiento y zona hotelera y del otro lado Akumal pueblo y Ciudad Chemuyil. Los pueblos al poniente de los centros turísticos, al oriente de la carretera son nombrados como pueblos de apoyo ${ }^{10}$.

El tercer punto a abordar en este apartado de conflictividad es el despoblamiento de las zonas rurales. Según INEGI (2016), la distribución de la población muestra de Quintana Roo tiende a la urbanización, con el 80\% de su población residiendo en localidades de 15, 000 o más habitantes. Concentrándose en determinadas áreas, principalmente en la parte costera del estado y su dispersión hacia el interior, en localidades con menos de 2500 habitantes (11.1\%). Las principales ciudades son Cancún, Chetumal, Playa del Carmen y Tulum, así como en Islas Mujeres y Cozumel

Otro indicador del abandono de las zonas rurales lo da la población de 12 años o más ocupada en su gran mayoría en el sector comercio y servicios (80.1\%), seguido del $13.4 \%$ en el sector industrial y de la construcción y finalmente el agropecuario con el 5.4\%. Desde 2000 a 2015 se ha observado la disminución de los sectores agropecuario e industrial, pasando de 9.9 a $5.4 \%$ y de 15.6 a 13.4 por ciento, respectivamente. Mientras que el sector terciario continúa en crecimiento, pasando de $72.7 \%$ de la población ocupada al $80.1 \%$. El sector servicios por regla se desarrolla en el ámbito urbano, por lo que también observamos que según posiciones en el trabajo el $77.9 \%$ son trabajadores asalariados, $16.2 \%$ trabajadores por su cuenta, $2.9 \%$ empleadores y $2.2 \%$ trabajadores sin pago. Porcentajes que nos indican la dinámica de disminución de actividades del ámbito rural, con determinadas consecuencias que presentaremos a continuación.

La conformación de las zonas turísticas del estado ha requerido mano de obra para la construcción de la infraestructura y posteriormente para cubrir los puestos de trabajo como camareras, cocineros, jardineros, choferes, entre otros. Todo el estado ha contribuido con la integración de la clase trabajadora del norte y litoral, sin embargo, es más evidente la migración desde la zona centro, la zona maya y agrícola. La migración, definitiva y estacional, está llevando a la transformación de campesinos milperos y de ejidatarios a trabajadores temporales. Teniendo asegurada una mínima superficie de milpa, los pobladores rurales migran a buscar trabajo como albañil, camarero entre otros, en la zona turística. Pero regresa a su pueblo "combinando el salario con los ciclos de la naturaleza, manteniendo y modificando así el sentido actual de la cultura maya" (RAMÍREZ CARRILLO, 2006: 81).

En diferentes trabajos (RAMÍREZ CARRILLO, 2006; BALAM, 2010; CASTELLANOS y MACHUCA, 2008) se establece que el trabajo en el sector turismo, como parte de la migración temporal, impacta en los siguientes elementos: orden de la economía, Jerarquías tradicionales, organización familiar y transformación de valores tradicionales en cuanto a expectativas de vida, tipos de consumo, prácticas sexuales, atuendo, espacios domésticos y tipos de vivienda.

Otro punto que se ha destacado como transformación de lo rural es la dinámica de muchos de los trabajadores de las zonas hoteleras que se desplazan diariamente de sus comunidades de origen hacia sus centros de trabajo. Llegan a invertir hasta 3 horas de camino en el transporte que el hotel

\footnotetext{
${ }^{10}$ Los pueblos de apoyo son "localidades fundadas a partir de los enclaves turísticos" (VÁZQUEZ SOSA, et. al., 2015), habitados por inmigrantes de origen rural que llegan a trabajar a los complejos turísticos. En un primer momento las empresas brindan hospedaje y alimentación a los trabajadores pero después ellos mismos forman redes de apoyo para construir un asentamiento con viviendas y sitios de esparcimiento.
} 
dispone. Estos trayectos largos y cansados han sido defendidos por los propios hoteleros porque contribuyen a no "no desarraigarlos de su comunidad", pero sobre todo son la forma en que bajan los costos en hospedaje, infraestructura urbana y servicios de salud (FRAGA BERDUGO, 2012: $53)$.

\section{CONSIDERACIONES FINALES}

Tres aspectos a destacar para cerrar este trabajo: la importancia de la categoría de conflictividad social; el enfrentamiento de territorialidades que han configurado conflictivamente al estado de Quintana Roo y, el reconocimiento de diferentes agentes sociales que con sus prácticas y discursos construyen y re construyen el territorio.

Conflictividad socio- territorial es la categoría que permite retomar dos procesos: el conflicto manifiesto y el conflicto latente. El primero refiere a los elementos estructurales evidentes, instrumentales, estratégicos de cualquier disputa. Mientras el segundo retoma los contextos que anteceden a un conflicto manifiesto (contextos de tensión) y también donde la confrontación parece desaparecer, pero sin resolver los factores estructurales de la problemática (los intereses contrapuestos sobre el territorio no desaparecen).

Cabe destacar este segundo proceso que configura la conflictividad socio- territorial, para lo cual retomamos la propuesta de Madrigal González que habla de procesos de no conflicto refiriéndose a un conjunto de interacciones, discursos y prácticas atravesadas por una determinada distribución de poder y de formas de violencia no explícitas, pero sobre las cuales se construye la dominación territorial a partir de ciertos intereses, valoraciones y formas de conocimiento sobre otros (MADRIGAL GONZÁLEZ, 2014: 63). Hablamos pues de un estado de tensión permanente que se ha "traducido" en un estado de no conflicto, una forma de "armonía bajo tensión".

La mirada sobre los conflictos, con la perspectiva socio- territorial permite abordar a los agentes sociales (con distintos intereses, valores, culturas, saberes), su grado de poder y sus prácticas de dominación- apropiación del territorio. Entonces se avanza sobre la perspectiva de la conflictividad social, es decir, donde las disputas tienen dimensiones múltiples nacidas de las propias contradicciones estructurales y que se manifiestan en los intereses incompatibles, en los antagonismos.

En cuanto al enfrentamiento de territorialidades en Quintana Roo vale la pena traer a la mesa dos planteamientos que pueden ser complementarios para explicar los conflictos y los respectivos cambios en el mundo rural por el enfrentamiento de las racionalidades. Por una parte, está el trabajo de FERNANDES MANCANO (2007) que establece que el enfrentamiento de modelos de desarrollo -agronegocios y en este caso turismo, frente al campesinado- produce territorios aparejados con conflictos casi irresolubles porque la expansión de uno implica la destrucción del otro. La otra propuesta es la de León (op. cit.) quien enuncia que el capitalismo, se reinventa a través de la estrategia socio- espacial de la fragmentación del sustrato de vida campesina, haciendo de la reglamentación como su principal instrumento para lograr el uso privado de los recursos territoriales.

De Fernandes se retoma la idea de que la nueva configuración territorial implica la redistribución de actividades económicas y formas de utilizar los recursos, hay cambios por el modelo turístico, se modifican los usos del espacio, existe una ruptura con los marcos institucionales y las regulaciones estatales tradicionales. Además, Fernandes enfatiza en la velocidad de territorialización del capital que es mayor al del campesinado, pues generando desigualdades pone en desventaja al campesinado; mientras que este último se territorializa a través de la lucha popular y de las políticas públicas.

En cuanto a la tesis de León (op. cit.) se toma el concepto de fragmentación para explicar el proceso de desvinculación de la tierra mediante legislaciones independientes que fortalecen la apropiación privada y concentración monopólica. Lo cual implica que exista un doble proceso, por un lado, la acumulación originaria, es decir, la separación de las comunidades campesinas de sus medios materiales de subsistencia (despojo de la tierra) y la fragmentación, despojo y administración independiente de cada uno de los fragmentos, de tierra, agua, bosques, diversidad genética, viento y ciclos naturales. La fragmentación neoliberal del sustrato material del territorio campesino implica romper con la unidad territorial, pues cada una de las partes es entregada al 
capital privado nacional o internacional, imponiendo nuevas prácticas, aunque no se utilicen esquemas de propiedad privada de la tierra.

Finalmente, partiendo de una escala local son los agentes comunitarios los que se esperaría tengan centralidad en las prácticas de conservación en sus territorios, sin embargo, en la realidad se observa que los Organismos No gubernamentales han cobrado relevancia. Bajo el discurso de la sustentabilidad los agentes externos han incidido en las dinámicas comunitarias. Enarbolando el "beneficio de las generaciones futuras y el progreso de los habitantes locales", se implementan actividades ambientalmente amigables no agrarias, como el ocio y los servicios. Es entonces que se puede decir que muchos de los proyectos que han llegado de fuera a las comunidades están refuncionalizando la conservación comunitaria con objetivos mercantiles.

La conservación comunitaria, aunque tenga antecedentes históricos fuertes, en la actualidad se construye constantemente desde distintos frentes: desde las políticas públicas que delimitan las acciones de los agentes, los proyectos apoyados por las Organizaciones No Gubernamentales (ONG's) y, las prácticas cotidianas de los agentes comunitarios y pobladores en general. Por lo tanto, la conservación en espacios comunitarios está delineada por la confluencia y la pugna entre los agentes por la gestión del espacio. En esta situación los agentes comunitarios toman elementos discursivos y de prácticas que las instancias gubernamentales u ONGs manejan y las relaboran, de esta manera se reterritorializan.

Así entonces, existen esquemas de valoración de los recursos naturales y formas de apropiación divergentes. Hay una enorme diferencia entre la valoración económica y la cultural. La primera destaca el valor monetario de la naturaleza, ya sea por los beneficios directos obtenidos gracias a su explotación -como la pesca-, o por los usos indirectos -los recorridos turísticos de apreciación de la naturaleza-. Mientras que la cultural se basa en los manejos tradicionales que una población ha hecho por generaciones del medio en el que viven. Sin embargo, ambas coexisten, se enfrentan, se superponen, siendo fuente de conflictividad en los espacios comunitarios. Se observa que los espacios comunitarios se han complejizado por la coexistencia e interacción de los diferentes agentes sociales.

\section{BIBLIOGRAFÍA}

ALAVEZ SAN PEDRO, M. et al. 2017. "Migración y violencia en Cancún: estudio de dos asentamientos irregulares". Revista nuestrAmérica, vol. 5, no. 10, pp. 67- 89

ARCHER, SCOTFORD, M. (Daniel Chernilo, traductor). 2009. Teoría social realista: el enfoque morfogenético. Santiago de Chile: Universidad Alberto Hurtado. 452 pp.

BALAM RAMOS, Y.H. 2010. Tulum: mayas y turismo. Quintana Roo: UQROO, 380 pp.

BOLÍVAR, A. y CUÉLLAR, O. 2008. "Rousseau sociólogo: para una teoría del funcionamiento del Estado". Revista latinoamericana [en línea]. Disponible en:<http://www.redalyc.org/articulo.oa?id=30501911>. [Fecha de consulta: 23 de octubre de 2016].

BRAY, D.B.y L. MERINO PÉREZ. 2005. La experiencia de las comunidades forestales en México. México: CCMSS, INE, SEMARNAT. 209 pp.

BÜSCHER, B. et al. 2012. "Towards a Synthesized Critique of Neoliberal Biodiversity Conservation". Capitalism Nature Socialism, Vol. 23, Number 2, June.

CALDERÓN MALDONADO, J.J. 1999. Viabilidad del Plan de Manejo Forestal en dos ejidos de la zona sur de Quintana Roo: tres Garantías y Guadalupe Victoria. Tesis. Quintana Roo: UQROO.

CAPEL SÁEZ, H. 2012. Filosofía y ciencia en la Geografía contemporánea. Una introducción a la Geografía -Nueva edición ampliada (la estrella polar). Barcelona: Ediciones del Serbal. $477 \mathrm{pp}$.

CARDONA RESTREPO, P. 2008. "Poder político, contrato y sociedad civil: de Hobbes a Locke". Revista Facultad de Derecho y Ciencias Políticas, Vol. 38, No. 108, p. 123- 154.

CASTELlANOS, A. y MACHUCA, J.A. (compiladores). 2008. Turismo, identidades y exclusión. México: Universidad Autónoma Metropolitana- Casa Juan Pablos, 253 pp. 
CASTILLO, O. y A. J. VILLAR. 2011. "La conformación del espacio urbano de Cancún: una aproximación al estudio de la segregación socio- espacial”. Quivera, Vol. 13, Núm. 1- Toluca: Universidad Autónoma del Estado de México.

DOMÍNGUEZ, D. y SABATINO, P. 2008. "El conflicto por la tierra en la actualidad latinoamericana: del acceso a la tierra a la lucha por el territorio". Informe final del concurso: Las deudas abiertas en América Latina y el Caribe. Programa Regional de Becas CLACSO. Disponible en: http://bibliotecavirtual.clacso.org.ar/ar/libros/becas/2008/deuda/doming.pdf

FERNANDES MANCANO, B. 2007. "Cuestión agraria: conflictualidad y desarrollo territorial". Texto preparado para el Seminario en el Lincoln Center Institue of Land Policy y en Harvard University. Disponible https://web.ua.es/en/giecryal/documentos/documentos839/docs/bmfunesp-2.pdf, [consultada 13 de enero 2017].

FLORES LUIS, S. G. 2013. Dinámicas socioterritoriales en los espacios de conservación de la Reserva de la Biosfera Sian Ka'an, Quintana Roo, México. Tesis Maestría. FFyL, IIGUNAM.

FOLCHI DONOSO, M. 2001. "Conflictos de contenido ambiental y ecologismo de los pobres: no siempre pobres, ni siempre ecologistas", Ecología Política, núm. 22, pp. 79- 101.

FRAGA BERDUGO, J. 2012. "Migración y turismo en la Riviera maya a través de dos pueblos del mundo maya". Marín, G., A. García de Fuentes y M. Daltabuit (Coords.). Turismo, globalización y sociedades locales en la península de Yucatán, México. España: Asociación Canaria de Antropología- PASOS, Revista de Turismo y Patrimonio Cultural, p. 45- 74.

GUERRERO, P. 1999. "Aproximaciones conceptuales y metodológicas al conflicto social”. En Pablo Ortíz (comp.), Comunidades y conflictos socioambientales: experiencias y desafíos en América Latina. Quito: Ediciones UPS/ Abya- Yala, pp. 35- 88.

INEGI. 2018. Marco geoestadístico. Instituto Nacional de Estadística y Geografía. https://www.inegi.org.mx/temas/mg/ [consulta: 13 de enero de 2019].

INEGI. 2016. Principales resultados de la Encuesta Intercensal 2015, Quintana Roo. Instituto Nacional de Estadística y Geografía. 92 pp.

LEFEBVRE, H. 1976. Espacio y política: El derecho a la ciudad II, Barcelona: Península. 176 pp.

LEÓN HERNÁNDEZ, E. 2011. "Territorialidad campesina y contrarreforma agraria neoliberal en México". En Descubriendo la espacialidad desde América Latina. México: Editorial Itaca, pp. 179- 208.

LÓPEZ SANTILLÁN, A.A. 2012. "Desarrollo turístico e inequidad: el caso de Mahahual en Costa Maya, Quintana Roo". Marín, G., A. García de Fuentes y M. Daltabuit (Coords.). Turismo, globalización y sociedades locales en la península de Yucatán, México. España: Asociación Canaria de Antropología- PASOS, Revista de Turismo y Patrimonio Cultural, p. 109- 138.

LORENZO CADARSO, P.L. 1995. "Principales teorías sobre el conflicto social". Norba. Revista de historia, número 15. p. 237- 254.

MACÍAS ZAPATA, G.A. 2002. La Península fracturada. México: CIESAS- UQROO, 340 pp.

MADRIGAL GONZÁLEZ, D. 2014. "Conflictos y No Conflictos en el Valle de San Luis Potosí. Análisis de la dimensión conflictiva de lo socioambiental a partir de dos casos". En F. Paz y N. Risdell (coords.), Conflictos, conflictividades y movilizaciones socioambibentales: problemas comunes, lecturas diversas. México: CRIM-UNAM, Miguel Ángel Porrúa, p. 6297.

ORTEGA VALCÁRCEL, J. 2000. Los horizontes de la geografía. España: Ariel Geografía.604 pp.

PONT- LEZICA, D.M. 2005. "Bosque nativo: conflictos de explotación”. Nómadas, número 22, pp. 164- 172.

PROPÍN, E., SÁNCHEZ, A. y ALVARADO, I. 2017. "Niveles de selectividad territorial de los destinos turísticos de México". Cuadernos de turismo, n 39. p. 495- 520.

PROPÍN, E. y SÁNCHEZ, A. 2002. "La estructura regional del turismo en México". Ería, núm., 59. p. 386- 394. 
RAMÍREZ CARRILLO, L.A. 2006. "Impacto de la globalización en los mayas yucatecos". Estudios de cultura maya, XXVII, pp. 73-97.

RANGEL, A. 2018. Quintana Roo Hoy, marzo, http://quintanaroohoy.com/chetumal/sin-control300-asentamientos-irregulares/ [consultada: 13 septiembre, 2018].

ROMERO MAYO, R.I. 2008. Turismo y polarización regional en Quintana Roo. Tesis. México: UNAM-FFyL.

RUBIO MALDONADO et. al. 2010. "Crisis ambiental en la costa de Quintana Roo como consecuencia de una visión limitada de lo que representa el desarrollo sustentable". Argumentos, Núm. 63, mayo- agosto. México: UAM.

SANDOVAL, B. 2011. De territorio salvaje, olvidado y prístino a paraíso turístico de dudosa conveniencia. Disquisiciones en torno a la transformación del noreste de Quintana Roo, 1902 1977. Tesis Doctorado. UNAM- FFyL.

SANTOS, M. 2000. La naturaleza del espacio. Barcelona: Ariel. 348 pp.

SCRIBANO, A. 2014. "Teoría crítica en América Latina: un bosquejo de sus posibles componentes". En Osorio, F. (editor). Epistemología y ciencias sociales: ensayos latinoamericanos. Santiago de Chile: LOM Ediciones. pp. 69-88.

Secretaría de Economía. 2018. Información económica y estatal. Quintana Roo. México: Gobierno federal.

TALLEDOS SÁNCHEZ, E. 2014. "La geografía: un saber político". Espiral, vol. XXI, núm. 61, septiembre- diciembre. p, 15- 49.

VÁZQUEZ SOSA, A., et al. 2015. "Pueblos de apoyo en contextos turísticos. Akumal, enclave turístico de la Riviera Maya de Quintana Roo". Temas Antropológicos, Revista Científica e Investigaciones Regionales, volumen 37, número 2, abril- septiembre. Mérida: Universidad Autónoma de Yucatán, pp. 121- 139.

VILLALOBOS GONZÁLEZ, M. 2015. Senderos de poder y autonomía, sociedad y posguerra en el territorio de Quintana Roo 1887- 1927. Tesis Maestría UNAM- FFyL. 